\title{
Historical changes in grassland area determined the demography of semi-natural grassland butterflies in Japan
}

\author{
Naoyuki Nakahama ${ }^{1}{ }^{1} \cdot K$ Kei Uchida ${ }^{2} \cdot$ Atushi Ushimaru $^{3} \cdot$ Yuji Isagi ${ }^{4}$
}

Received: 27 July 2017 / Revised: 27 November 2017 / Accepted: 9 January 2018 / Published online: 26 February 2018

(c) The Genetics Society 2018

\begin{abstract}
Semi-natural grassland areas expanded worldwide several thousand years ago following an increase in anthropogenic activities. However, semi-natural grassland habitat areas have been declining in recent decades due to changes in landuse, which have caused a loss of grassland biodiversity. Reconstructing historical and recent demographic changes in seminatural grassland species will help clarify the factors affecting their population decline. Here we quantified past and recent demographic histories of Melitaea ambigua (Lepidoptera; Nymphalidae), an endangered grassland butterfly species in Japan. We examined changes in demography over the past 10,000 years based on $1378 \mathrm{bp}$ of mitochondrial COI gene. We then examined changes in its genetic diversity and structure during the last 30 years using nine microsatellite DNA markers. The effective population size of M. ambigua increased about 3000-6000 years ago. In contrast, the genetic diversity and effective population sizes of many populations significantly declined from the 1980s to 2010s, which is consistent with a recent decline in the species population size. Our data suggest that the M. ambigua demography can be traced to changes in area covered by semi-natural grasslands throughout the Holocene.
\end{abstract}

\section{Introduction}

Worldwide, semi-natural grasslands have high biodiversity. Although these grasslands' biodiversity have been historically maintained by anthropogenic activities, such as fire, grazing, and mowing, this diversity has become threatened in recent decades mainly due to recent changes in landuse and management practices (Berg et al. 2011; Kleijn et al.

Electronic supplementary material The online version of this article (https://doi.org/10.1038/s41437-018-0057-2) contains supplementary material, which is available to authorised users.

$\square$ Naoyuki Nakahama

naoyuki.halobates@gmail.com

1 Graduate School of Arts and Sciences, The University of Tokyo, 3-8-1 Komaba, Meguro-ku, Tokyo 153-8902, Japan

2 Graduate School of Environment and Information Sciences, Yokohama National University, 79-7 Tokiwa-dai, Hodogaya-ku, Yokohama, Kanagawa 240-8501, Japan

3 Graduate School of Human Development and Environment, Kobe University, 3-11 Kobe, Hyogo 657-8501, Japan

4 Graduate School of Agriculture, Kyoto University, Kitashirakawa Oiwake-cho, Sakyo-ku, Kyoto 606-8502, Japan
2011; Suka et al. 2011; Amici et al. 2015). Therefore, there has been an increasing interest in conserving semi-natural grassland biodiversity worldwide (Kleijn et al. 2011; Amici et al. 2015). Because habitat loss and fragmentation are the primary drivers of reduction in grassland biodiversity (Amici et al. 2015; Bubová et al. 2015), a major subject of semi-natural grassland conservation is to determine the relationship between the area of semi-natural grassland habitats available and population sizes of endangered grassland species.

Forest vegetation could widely cover the temperate, humid zones of Eurasia after the last glacial period, although natural grasslands (e.g., azonal, extrazonal, riparian, and coastal) were also maintained due to specific soil or topographic conditions and natural disturbances (Miyawaki et al. 1975; Bohn et al. 2003; Yuan et al. 2011; Török and Dengler 2018). Instead, large semi-natural grassland areas (e.g., meadows and pastures) became established and were then maintained by anthropogenic activities (Isselstein et al. 2005; Kawano et al. 2012; Miyabuchi et al. 2012; Hejcman et al. 2013; Kuneš et al. 2015). Semi-natural grasslands expanded throughout Eurasia from the early Holocene until the early 20th century as pasturing and farming activities expanded (Hejcman et al. 2013; Török et al. 2018; Ushimaru et al. 2018). As European and East Asian countries 
experienced rapid economic growth following the shift from agriculture to manufacturing in the 20th century, grasslands used for pasture declined in economic value (Isselstein et al. 2005; Ushimaru et al. 2018). Further, unimproved and species-rich grasslands have rapidly declined in area as they became abandoned or were more intensively used since the late 20th century (Isselstein et al. 2005; Kleijn et al. 2011; Nakamura 2011; Suka et al. 2011; Bubová et al. 2015; Uchida et al. 2016; Török and Dengler 2018). Grassland species are affected by grassland area conversions. Many grassland plants and insect species have become threatened in Europe and Japan in recent decades in response to the loss of semi-natural grassland ecosystems (Kleijn et al. 2011; Nakamura 2011; Suka et al. 2011; Koyanagi and Furukawa 2013; Bubová et al. 2015). However, little is known on how grassland species populations have changed in concert with the increase in semi-natural grassland area during the early Holocene to the late 19th century. This is because historical population data for past millennia are difficult to obtain.

Today, the demographic history of wild species during the last thousands to millions of years can be revealed by examining mitochondrial, chloroplast, or nuclear DNA data (Drummond and Rambaut 2007). Specifically, the coalescent theory using mitochondrial DNA sequences whose mutation rates are usually high and stable can be used to reconstruct the demographic history of a given species from circa 10,000-100,000 years ago (Stojak et al. 2015). Furthermore, population genetic analyses of recent past and contemporary specimens can be used to examine changes in genetic diversity and structure, indicating changes in population size and changes during the intervening decades (Harper et al. 2006; Wandeler et al. 2007; Cousseau et al. 2016; Fountain et al. 2016). Although genetic analysis of specimen samples is generally difficult mostly due DNA degradation over time, using microsatellite markers with short polymerase chain reaction (PCR) products is helpful for overcoming these difficulties (Nakahama and Isagi 2017). Reconstructing historic and recent demographic changes of endangered, semi-natural grassland species using genetic makers is useful to help clarify factors affecting their demographic changes and provides a powerful tool to aid in conservation planning for species populations.

Grassland butterflies are strongly influenced by reduction in habitat areas worldwide (Nakamura 2011; Bubová et al. 2015). In the present study, we examined the demographic history of Melitaea ambigua (Lepidoptera; Nymphalidae), an endangered, semi-natural grassland butterfly species in Japan, using mitochondrial DNA sequence analysis of current samples and microsatellite analysis of specimens collected in past and more contemporary samples.
Unfortunately, there is little information regarding historical changes in distributions of semi-natural grasslands associated with the expansion of anthropogenic activities during the Holocene in Japan. During glacial periods, it is suggested the boreal natural grasslands and coniferousbroadleaved forests were dominant (Kawano et al. 2012; Miyabuchi et al. 2012). After the last glacial period, various forest types are the climatic climax vegetation in most terrestrial areas due to humid climate in Japan (Miyawaki et al. 1975; Ushimaru et al. 2018). Thus, both natural and seminatural grasslands have limited distribution within the country, as only ca. 5\% of the land maintains grassland conditions currently (Ushimaru et al. 2018).

Conversely, Andosols (kurobokudo, Japanese black soils), indicating the presence of fire over long periods since their formation following the last glacial period (Kawano et al. 2012; Miyabuchi et al. 2012), are widespread in semi-natural grasslands in Japan and currently cover about 17\% (Suka et al. 2011). This suggests that expansive semi-natural grasslands used to occur throughout Japan (Suka et al. 2011; Ushimaru et al. 2018). Since the late 19th century, semi-natural grassland areas have declined from $11 \%$ to only $1-3 \%$ of national lands and remnants are extremely fragmented (Ogura 2006; Suka et al. 2011; Ushimaru et al. 2018). We hypothesise that $M$. ambigua has rapidly declined in population size (indicated by the loss in genetic diversity and effective population size) in recent decades following the decline in semi-natural grassland area. This is in contrast to the expected increase in its population size during the Holocene. To test this hypothesis, we estimated the demographic history of M. ambigua populations during the last 10,000 years based on results from a coalescent analysis study using mitochondrial DNA sequences of more recently collected samples. We examined changes in genetic diversity and the structure, and effective population sizes of butterfly populations from specimens collected from the 1980s to the 2010s. These data were based on microsatellite analysis of specimens collected in the past 30 years and contemporary samples. Using these two sets of data, we investigated the effects of the decline in semi-natural grassland areas on the genetic diversity and effective population sizes of M. ambigua during recent decades. We discuss the importance of maintaining a sufficient semi-natural grassland area to maintain the population of this endangered species and outline a potentially effective conservation strategy based on our results.

\section{Materials and methods}

\section{Target species}

M. ambigua is endemic to grasslands in East Asia (Fig. S1, Shirouzu 2006). It used to be widely distributed several 
Table 1 The sample number and collected years of the 17 M. ambigua populations for microsatellite analysis and mtDNA sequencing in this study

\begin{tabular}{|c|c|c|c|c|c|c|c|c|}
\hline \multirow[t]{2}{*}{ Site ID } & \multirow[t]{2}{*}{ Country } & \multirow[t]{2}{*}{ Region } & \multirow{2}{*}{$\begin{array}{l}\text { Current } \\
\text { landuse }\end{array}$} & \multirow[t]{2}{*}{ Exist/extinct } & \multicolumn{3}{|c|}{ Number of samples for microsatellite analysis } & \multirow{2}{*}{$\begin{array}{l}\text { Number of samples for } \\
\text { mtDNA sequencing }\end{array}$} \\
\hline & & & & & $\begin{array}{l}1985 \\
(1980-1989)\end{array}$ & $\begin{array}{l}2000 \\
(1995-2003)\end{array}$ & $\begin{array}{l}2015 \\
(2011-2015)\end{array}$ & \\
\hline $\mathrm{a}$ & Japan & $\begin{array}{l}\text { Western } \\
\text { Nagano }\end{array}$ & Meadow & Exist & & & & $1(2015)$ \\
\hline $\mathrm{b}$ & & & Meadow & Exist & & $27(1995-2003)$ & $20(2014-2015)$ & 19 (2014-2015) \\
\hline $\mathrm{c}$ & & & Meadow & Exist & $19(1985-1989)$ & & $11(2014-2015)$ & $11(2014-2015)$ \\
\hline $\mathrm{d}$ & & & Pasture* & Exist & $28(1981-1988)$ & $14(1998-2003)$ & $20(2014)$ & $17(2014)$ \\
\hline $\mathrm{e}$ & & Hida & Meadow & Exist & & & & $2(2014-2015)$ \\
\hline $\mathrm{f}$ & & Chushin & Ski slope & Extinct & $8(1980-1988)$ & & $12(2013)$ & $3(2013)$ \\
\hline $\mathrm{g}$ & & & Tourist spot & Extinct & $22(1984)$ & $25(2000-2002)$ & $24(2011-2013)$ & $21(2011-2013)$ \\
\hline $\mathrm{h}$ & & & Tourist spot & Extinct & 17 (1985-1989) & 17 (1999-2002) & & \\
\hline $\mathrm{i}$ & & Azumino & $\begin{array}{l}\text { Cut-over } \\
\text { land }\end{array}$ & Exist & & & 25 (2014-2015) & 24 (2014-2015) \\
\hline $\mathrm{j}$ & & & Meadow* & Exist & & & 14 (2014-2015) & 14 (2014-2015) \\
\hline $\mathrm{k}$ & & Tohshin & $\begin{array}{l}\text { Cut-over } \\
\text { land }\end{array}$ & Extinct & & 18 (1997-1998) & & \\
\hline 1 & & & Meadow* & Extinct & $21(1984-1987)$ & & & \\
\hline $\mathrm{m}$ & & Johshin & $\begin{array}{l}\text { Cut-over } \\
\text { land }\end{array}$ & Exist & $17(1987)$ & 31 (1997-2002) & 20 (2014-2015) & 15 (2014-2015) \\
\hline $\mathrm{n}$ & & & Ski slope & Exist & 17 (1981-1984) & & 24 (2014) & 23 (2014) \\
\hline o & Russia & Primorsky & Unknown & Unknown & & & & $5(2008)$ \\
\hline $\mathrm{p}$ & & & Unknown & Unknown & & & & $3(2008)$ \\
\hline q & & & Unknown & Unknown & & & & 3 (2009) \\
\hline
\end{tabular}

Site ID, country, and exist/extinct are indicated for each population. The samples for microsatellite analysis were divided into three groups depending on the collected years

*Used for tourism

decades ago in temperate meadows and pastures in the central part of Japan in Nagano, Gifu, and Gumma Prefectures of the Chubu region (Shirouzu 2006). However, the size of this species population has rapidly declined due to the reduction in grassland area; therefore, it is currently categorised as 'endangered' in the Japanese Red List (Ministry of the Environment Government of Japan 2014). Veronicastrum japonicum var. japonicum and Melampyrum laxum var. nikkoense are the main host plants for the larvae of this butterfly whose main habitat is semi-natural grasslands and forest edge environments (Shirouzu 2006; K. Maruyama, personal observation). Because butterfly collectors for natural history museums in Japan and other collectors have preserved several $M$. ambigua specimens, we considered this species appropriate for reconstructing its demographic history based on genetic analyses.

\section{Study area and site}

Fourteen populations from Japan and three from Russia were investigated (Table 1, Fig. S2). The current landuses in Japan is described in Table 1, although it had been used for meadow and/or pasture before the 1940s (Suka et al. 2011). All populations from Japan were isolated from other populations by developed lands, forests, and high mountains. The remaining semi-natural grasslands were maintained by mowing and/or burning in the highlands. The annual mean temperatures in 1979-1985 and 2006-2015 were collected from the Automated Meteorological Data Acquisition System (AMeDAS; http://www.data.jma.go.jp/ $\mathrm{obd} /$ stats/etrn/index.php) nearest to each study site. Temperature data were corrected using the temperature lapse rate of $0.0065^{\circ} \mathrm{C} / \mathrm{m}$, the difference in the elevation between each study site and the nearest AMeDAS point (Table S1). The grassland area around each study site in Japan was examined with Q GIS (ver. 2.6.0) from 20 concentric, circular plots, wherein each nested plot's radius was 200-m longer than that of the plot within it. These plots were examined from 1947 to 1948,1975 to 1978 and 2010 to 2014 from aerial photographs acquired from the Geospatial Information Authority of Japan (http://mapps.gsi.go.jp/) and Google Earth (Google Earth (C) 2016 ZENRIN, 2016). Semi-natural grassland areas around each site reduced by more than half during the past 70 years (Table S1). Using Q 
GIS, we also measured the distance from the centroid of the nearest grassland patch to each study site for each period as an index for habitat fragmentation (Turner et al. 2001).

We examined the number of flowering species and vegetation height in July to assess vegetation conditions at each site. We set three $2 \times 30$-m belt plots at each site and counted the number of plant species that bloomed in 2014 and 2015. We measured vegetation heights at two points every $10 \mathrm{~m}$ at each belt plot ( 8 points/plot) in both years. We calculated the yearly means of these two variables for each site.

For the 12 populations in Japan (except sites a and e), 451 samples were collected for microsatellite analyses from recently captured individuals and collected specimens obtained from collections (Table 1). Sites a and e were removed from microsatellite analysis because we could neither estimate genetic diversity nor effective population sizes due to low sample sizes. We collected 149 samples for mitochondrial DNA sequencing analysis using recently captured individuals and young specimens (collected after 2013) from Japan (Table 1). Old specimens (collected before 2003) were omitted from mitochondrial DNA sequencing analysis due to highly fragmented DNA. We also used 11 samples from Russia (collected in 2008 and 2009) for mitochondrial DNA sequencing analysis to estimate the genetic distance and divergence time between Japanese and continental populations (Table 1).

\section{Sampling and DNA extraction}

DNA was extracted from wing or leg samples. A single middle or hind leg was collected from air-dried specimens (from 10 populations) captured during 1981 to 2013, which were preserved by natural history museums or butterfly collectors. Further, a small clip of hind wings $\left(1 \times 3 \mathrm{~mm}^{2}\right.$ in size) was collected from adult individuals we live-captured in 2014 and 2015. Removing small amounts of hind wings has no significant impact on the behaviour or survival of Nymphalidae adult butterflies (Hamm et al. 2010). All captured individuals were immediately released after removing wing samples.

Samples were categorised into three groups based on the collection year: samples collected from 1980 to1989 (hereafter referred to as 1985 samples), samples collected from 1995 to 2003 (hereafter referred to as 2000 samples), and samples collected from 2011 to 2015 (hereafter referred to as 2015 samples). In total, 465 samples were used for microsatellite analyses and/or mitochondrial sequencing analysis (Table 1).

Genomic DNA of wing and leg samples was extracted using the standard phenol-chloroform method. During DNA extraction, samples were incubated using CTAB buffer with proteinase $\mathrm{K}(5 \mu \mathrm{L}$ of $20 \mathrm{mg} / \mathrm{mL})$; wing samples were incubated for one night, while leg samples were incubated for two nights. Extracted DNA was eluted in 30 $\mu \mathrm{L}$ TE buffer.

Live samples could not be collected at five sites in Japan (sites f, g, h, k, and l) because we did not encounter any individuals during our field sampling and there were no known captures by collectors at these sites during 2014 and 2015. We therefore considered the butterfly to be putatively extinct in these locations (Table 1).

\section{Molecular analysis}

For mitochondrial DNA sequencing, two primer pairs were used to amplify 1378 base pairs of the COI gene from 161 samples collected in Japan and Russia. Sequencing details are described in Appendix A1.

The genotypes of samples were clarified at nine microsatellite loci characterised by Nakahama et al. (2015): Mam011, Mam013, Mam016, Mam017, Mam020, Mam023, Mam026, Mam028, and Mam031. These markers were designed for microsatellite analysis of specimen samples (Nakahama and Isagi 2017). The genotyping protocol for microsatellite analysis is described in Appendix A2. Micro-Checker v2.2.3 (Van Oosterhout 2004) was used (10,000 Monte Carlo simulations and 95\% confidence interval (CI)) to check for null alleles to identify errors due to large allele dropout.

\section{Mitochondrial DNA alignment and sequence analysis}

Mitochondrial sequence data were edited and aligned using the automatic multiple sequence alignment algorithm implemented in the ClustalW algorithm (Higgins et al. 1994) in MEGA 6.06 (Tamura et al. 2013). Our sequences have GenBank accession numbers LC279363-LC279512 (in Japan) and LC279513-LC279523 (in Russia). Further, a median-joining haplotype network of $M$. ambigua samples in Japan and Russia was inferred using NETWORK v. 4.6.1.3 (Bandelt et al. 1999).

\section{Demographic analysis}

To estimate the demographic expansion of M. ambigua collected in Japan, mitochondrial DNA sequences of samples collected from Japan were used to determine segregating site distribution (Tajima's D) and haplotype distribution (Fu's FS). Statistical expectations are nearly zero in a constant population size; significant negative values indicate sudden population expansion, whereas significant positive values indicate population subdivision or recent bottlenecks. The significances of D and FS statistics were tested by generating 10,000 coalescent simulations in 
ARLEQUIN v. 3.5 (Excoffier et al. 2005). To further investigate the possibility of demographic expansions, the distribution of pairwise sequence differences (mismatch distribution) for COI haplotypes were plotted using ARLEQUIN v. 3.5 (Excoffier et al. 2005). The goodnessof-fit between the observed and expected distributions of the sudden expansion model was calculated using the sum of squared deviations (SSD).

For samples collected from Japan, historical population dynamics of $M$. ambigua through time were estimated using a coalescent-based, Bayesian skyline plot without the assumption of any particular demographic model (Drummond and Rambaut 2007). The posterior probability distribution of effective population size $\left(N_{\mathrm{es}}\right)$ was estimated using BEAST v. 2.1.3 (Drummond and Rambaut 2007) by applying the best-fit model of nucleotide substitutions and their parameter values as priors. The COI nucleotide substitution rate was set to the average value commonly found in arthropods (1.77\% divergence lineages ${ }^{-1} \mathrm{Myr}^{-1}$, Papadopoulou et al. 2010) with a strict molecular clock. Markov chain Monte Carlo (MCMC) samplings were run for $1.0 \times$ $10^{8}$ generations with parameters sampled for every $1.0 \times$ $10^{4}$ generation. The initial $10 \%$ of the run was discarded as burn-in. Each analysis was repeated multiple times to optimise scale factors until no suggestion message appeared on the log file. The HKY evolutionary substitution model was used as selected in JModeltest v. 2.1.7 (Darriba et al. 2012) based on the Akaike information criterion (AIC) value. The effective sample size for the posterior distribution of estimated parameter values was determined using TRACER v. 1.6 (Rambaut et al. 2014). An a posteriori distribution of time to recent common ancestor (tMRCA) was obtained between the Japan and Russia. Analytic conditions were the same as they were for the above analysis.

\section{Statistical analysis of genetic diversity, effective population size, and genetic structure}

The genetic diversity of each population in each period was evaluated in terms of Nei's unbiased expected heterozygosity $\left(H_{\mathrm{E}}\right)$, observed heterozygosity $\left(H_{\mathrm{O}}\right)$, average number of alleles per locus $(A)$, and allelic richness $\left(A_{\mathrm{R}}\right)$. All parameters were calculated using FSTAT ver. 2.9.3 (Goudet 2001). $H_{\mathrm{E}}$ and $A_{\mathrm{R}}$, calculated by FSTAT ver. 2.9.3, are corrected indices for differences in sample size for each population. Effective population size $\left(N_{\mathrm{e}}\right)$ was estimated using two different single sample estimators for $N_{\mathrm{e}}$ in each period. (1) $N_{\mathrm{eSIB}}$ was estimated using the sibship assignment method implemented in Colony2 2.0.5.9 (Wang 2009). We used the full likelihood method with a weak prior probability, assuming random mating and polygamy. (2) $N_{\text {eLD }}$ was estimated using the linkage disequilibrium method implemented in NEESTIMATOR 2.1 (Do et al. 2014), wherein we used a minimum allele frequency of 0.02 and generated $95 \%$ CI by jackknifing.

Genetic relationships were evaluated among six populations (sites c, d, f, g, m, and $\mathrm{n}$ ) in the 1985 and 2015 samples using Bayesian clustering in STRUCTURE ver. 2.3.4. (Pritchard et al. 2009), which assigns individuals to $K$ clusters. Population structure was simulated with $K$ values of 1-7 under an admixture model and a correlated allele frequency model. All runs involved $1 \times 10^{6} \mathrm{MCMC}$ generations after a burn-in period of $1 \times 10^{6}$ iterations. Twenty runs were performed for each $K$ value. Cluster number was determined by comparing means and the variability of log likelihoods in each run. To select the optimal $K$ value, STRUCTURE Harvester (http://taylor0. biology.ucla.edu/structureHarvester/) was used. The $F$ value (amount of genetic drift between each cluster and a common ancestral population) and $H_{\mathrm{E}}$ were calculated. Analysis was separately conducted for 1985 and 2015 samples.

The genetic differentiation level was estimated for all pairs of the six populations in the 1985 and 2015 samples with $F_{\text {ST }}$ calculated using FSTAT 2.9 .3 (Goudet 2001). FSTAT 2.9.3 gives a $95 \% \mathrm{CI}$ for each global $F_{\mathrm{ST}}$ value. If there was no overlap of CIs for the two time periods, the global $F_{\mathrm{ST}}$ values were considered to significantly differ.

Recent migrations among the six populations in the 1985 and 2015 samples were estimated using BayesAss 3 (Wilson and Rannala 2003). We ran the programme with $1.5 \times$ $10^{8}$ MCMC iterations and sampled at every 15,000 steps. In runs using genetic data from 1985 and 2015 samples, the delta value for migration rates, allele frequencies, and inbreeding coefficients were set to $0.70,0.80$, and 1.00 , respectively, to ensure that acceptance rates for proposed changes to these parameters fell between $20 \%$ and $60 \%$, as suggested by the software manual. The first $1.5 \times 10^{7}$ iterations were discarded as burn-in after checking for the convergence of each parameter using TRACER v. 1.6 (Rambaut et al. 2014).

\section{Factors influencing genetic diversity and effective population size}

The effects of past (approximately 40 years prior) and recent (1-10 years prior) grassland area on genetic diversity and effective population sizes were examined using a linear mixed model (LMM). In the LMM, the response variable was $A_{\mathrm{R}}$ or $H_{\mathrm{E}}$ for each locus, or $N_{\mathrm{eSIB}}$ for the 1985 or 2015 samples collected from 11 Japan populations (except for sites a, e, and k). The $N_{e S I B}$ at site c collected in 2015 and site f collected in 1985 and 2015 were excluded from the response variable because $N_{\mathrm{eSIB}}$ or its $95 \%$ CIs were indicated as infinity. The $N_{\mathrm{eLD}}$ was also omitted from the response variable because with finite $\mathrm{CI}$ it was estimated 
only for sites $\mathrm{b}, \mathrm{c}$, and $\mathrm{n}$. The explanatory variables were the past or recent grassland area around each study site based on each of the 20 spatial scales (from concentric circular plots) and the mean annual temperature (mean temperatures during 1979-1985 and 2006-2015). Because there was a strong, significant correlation between the grassland area (radius: $200-4000 \mathrm{~m}$ ) and the distance from the centroid of the nearest grassland patch (for all radii: $\mathrm{r}>0.65, P<0.001$, Pearson's correlation test), we omitted the latter from the explanatory variable. Site and locus identities and site identity alone were included as the random terms for $A_{\mathrm{R}}$ and $H_{\mathrm{E}}$ and for $N_{\mathrm{eSIB}}$ LMMs, respectively. The grassland areas in 1947-1948 and 1975-1978 were defined as historical grassland areas associated with the 1985 and 2015 samples, respectively. Genetic diversity data for the 2000 samples was not included because we could not obtain photos or maps around those study sites. We constructed $82 A_{\mathrm{R}}$ (or $\left.H_{\mathrm{E}}\right)$ LMMs with two explanatory variables defined as both, neither or none of the grassland areas (historical or recent area at the 20 spatial scales sampled) and mean annual temperature. We also constructed $42 N_{\text {eSIB }}$ LMMs with a single explanatory variable because a multiple regression model is likely unsuitable due to few data points $(n=20)$ in $N_{\text {eSIB }}$ model. The model with the lowest AIC was selected as the best-fit model.

The effects of current vegetation conditions and past or recent grassland area on current genetic diversity and effective population sizes were also examined using a LMM and a linear model (LM), respectively. The response variable was $A_{\mathrm{R}}$ or $H_{\mathrm{E}}$ for each locus or $N_{\mathrm{eSIB}}$ of the 2015 samples. The explanatory variable was the past or recent grassland area, mean number of flowering species, mean vegetation height, and mean annual temperature. Each locus identity was included as random terms for $A_{\mathrm{R}}$ and $H_{\mathrm{E}}$ LMMs. For $N_{\text {eSIB }}$ LMs, we included only a single explanatory variable as in the above analysis. The model selection details were the same as the above analysis. All statistical procedures were performed using $\mathrm{R}$ ver. 3.2.1 and the package lme 4 , except $N_{\mathrm{eSIB}} \mathrm{LMs}$, which were performed using the package stats (R Development Core Team 2015).

\section{Results}

\section{Demographic history analyses based on mitochondrial DNA}

We determined $1378 \mathrm{bp}$ of COI sequences for 161 individuals in Japan and Russia. We observed 21 haplotypes within both populations and 17 haplotypes within 14 populations in Japan. The haplotype network tree for the populations in Japan resulted in a star-like distribution, with

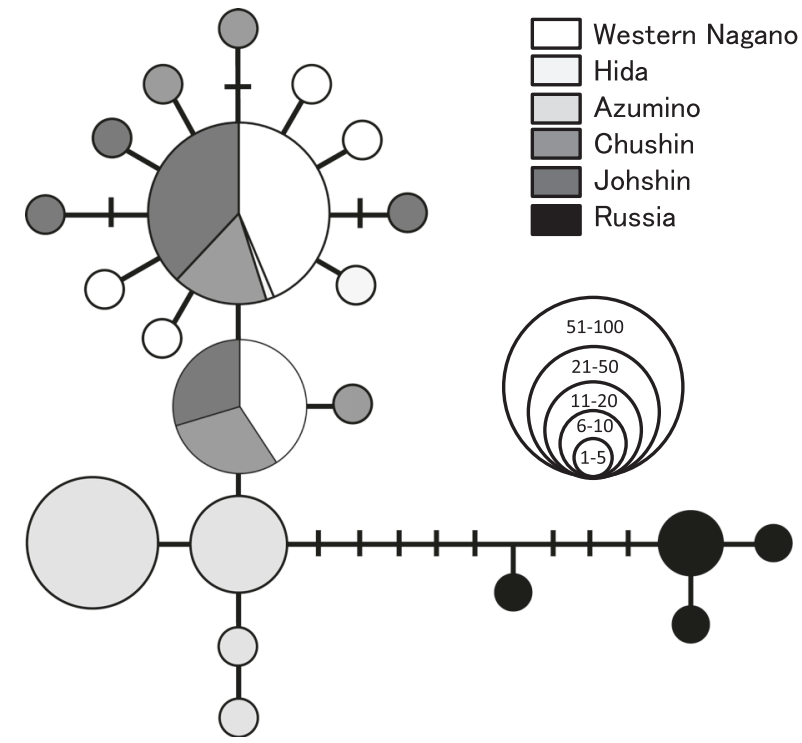

Fig. 1 Haplotype network for the mitochondrial COI gene of $1378 \mathrm{bp}$ from 161 individuals collected from 14 sites in Japan and three sites in Russia. Line distance between circles corresponds to the number of nucleotide differences (one or two). Each circle represents a unique haplotype, and the area of each circle corresponds to the number of individuals with that haplotype (the smallest circles are singletons). Vertical bars along lines are presumptive intermediate haplotypes that were not observed

the most frequent haplotypes located in the centre of the network tree, surrounded by several lower-frequency haplotypes, a pattern typically observed in expanding populations (Fig. 1). Except for the Azumino butterfly population, no clear genetic differentiation was found, although there were 6-9 missing intermediate haplotypes between Japan and Russia.

Fu's FS values for the populations in Japan were significantly lower than zero ( $\mathrm{FS}=-8.45800, P<0.01$ ). Tajima's D metric for the populations was also significantly different from zero $(\mathrm{D}=-1.58454, P<0.05)$. Mismatch analysis revealed no significant deviation from the expectation of the null model, which assumed a population expansion of the populations in Japan ( $\mathrm{SSD}=0.005, P=$ 0.602; Fig. S3). Furthermore, the Bayesian skyline plot for populations in Japan (with 95\% highest posterior density (HPD)) demonstrated that they had undergone a major growth phase, commencing approximately $10,000 \mathrm{ybp}$ (years before present). The effective size of the Japan populations drastically increased during the $3000 \mathrm{y}$ period approximately 3000-6000 y bp (Fig. 2). After this, the population grew rapidly, with an approximately 130-fold increase since the end of the last glacial period around $12,000 \mathrm{ybp}$. tMRCA between the Japan and Russia was estimated to be 72,000 y bp (95\% HPD $=21,000-148,000$ $\mathrm{y} \mathrm{bp}$ ) based on a substitution rate of $1.77 \mathrm{Myr}^{-1}$. 


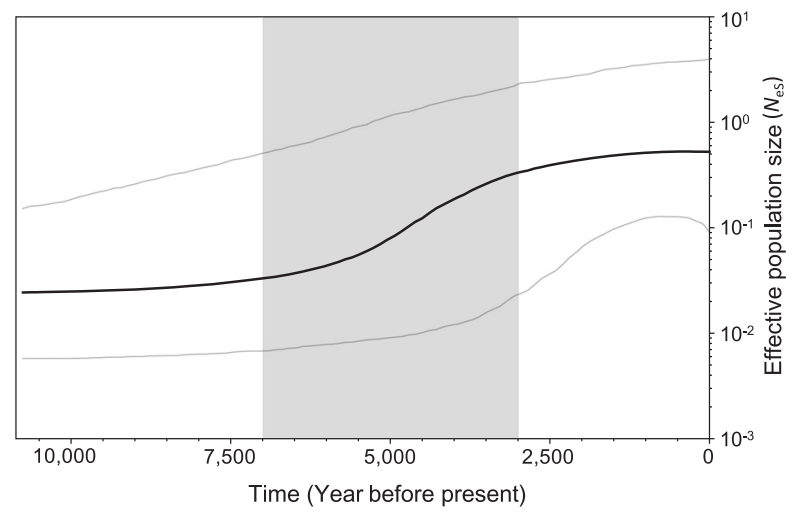

Fig. 2 Bayesian skyline plot of samples in Japan based on the COI gene. Substitution rates of $1.77 \%$ divergence lineages ${ }^{-1} \mathrm{Myr}^{-1}$ were used. The dark solid line is the median estimate, and blue lines show the $95 \%$ highest posterior density limits. Effective sample size values are $>250$ for all parameters. The grey translucent box indicates the period over which grasslands expanded in area in Japan based on phytolith and charcoal data (in Andosols) (Suka et al. 2011; Kawano et al. 2012; Miyabuchi et al. 2012; Yoshida et al. 2016) (Colour figure online)

\section{Recent changes in genetic diversity and structure by microsatellite analyses}

Missing data for microsatellite analyses constituted only $1.87 \%$ of all samples and loci. Micro-Checker 2.2.3 revealed that locus Mbn031 had null alleles in the 1985 samples from sites $d$ and 1 . There was no evidence of a substantial allele dropout. When we applied Bonferroni correction for multiple testing, we found no significant linkage disequilibrium between any pair of loci for any sample year in either population.

The mean $A_{\mathrm{R}}$ and $H_{\mathrm{E}}$ at all the sites and periods are described in Table S2. The $N_{\text {eSIB }}$ with finite CI was estimated for all populations except the samples from site c collected in 2015 and site f collected in 1985 and 2015 (Table S2). Conversely, the $N_{\text {eLD }}$ with finite CI was estimated only for sites b, c, and n collected in 2015 (Table S2). For all samples, $N_{\mathrm{eSIB}}$ positively correlated with the mean $A_{\mathrm{R}}$ and $H_{\mathrm{E}}\left(A_{\mathrm{R}}: \mathrm{r}=0.58, P=0.007 ; H_{\mathrm{E}}: \mathrm{r}=0.48, P=0.03\right.$; Pearson's correlation test).

The mean $A_{\mathrm{R}}, H_{\mathrm{E}}$, and $N_{\mathrm{eSIB}}$ of the 2000 and/or 2015 samples were lower than those of the 1985 samples in many populations we examined (Table S2, Fig. S4); we found a decline in grassland area since the 1940s in all sites. The best models for $A_{\mathrm{R}}, H_{\mathrm{E}}$, and $N_{\mathrm{eSIB}}$ in all the periods included only one explanatory variable: grassland area in the recent past $(40 \mathrm{y} \mathrm{bp})$ within $1200-\mathrm{m}$ radius circles. The best models for $N_{\mathrm{eSIB}}$ in all periods included grassland area in the recent past ( $40 \mathrm{y} \mathrm{bp}$ ) within $1200-\mathrm{m}$ radius circles as the explanatory variable. This indicates that genetic diversity and effective population sizes significantly decreased within the recent past, and this decrease was unaffected by changes in the mean annual temperature (Table 2 and S1, Fig. 3).

The best model for current $A_{\mathrm{R}}$ included three explanatory variables: grassland area in the recent past $(40 \mathrm{y} \mathrm{bp})$ within 1200-m radius circles, the number of flowering species and the mean annual temperature. Conversely, the best model for current $H_{\mathrm{E}}$ included one explanatory variable: grassland area in the recent past $(40 \mathrm{y} \mathrm{bp}$ ) within $1200-\mathrm{m}$ radius circles. The best model for current $N_{\text {eSIB }}$ included grassland area in the recent past ( $40 \mathrm{y} \mathrm{bp)}$ within $200-\mathrm{m}$ radius circles as the explanatory variable.

STRUCTURE analysis of the six populations indicated that the M. ambigua populations exhibited a clear spatial clustering of genetic characteristics in the 1985 and 2015 samples (Fig. 4). The $\Delta K$ value was highest at $K=2$ in the 1985 and 2015 samples (Figs. S5A, B). Further, the $\Delta K$ value was high at $K=3$ in the 2015 samples (Figs. $\mathrm{S} 5 \mathrm{~B})$. This indicates that genetic clusters tended to be divided into three regions in the 2015 samples: the Western Nagano (c and d sites), Chushin (f and g sites), and Johshin ( $\mathrm{m}$ and $\mathrm{n}$ sites) clusters (Fig. 4b). However, genetic differentiation between the Chushin and Johshin populations was not clearly identified in the 1985 samples (Fig. 4a). When we conducted STRUCTURE analysis using nine current populations in Japan, the $\Delta K$ value was highest at $K=3$ (Fig. S5C) and genetic clusters were differentiated into the Western Nagano, Azumino, and Chushin + Johshin regions (Fig. 4c).

The $F_{\mathrm{ST}}$ values between population pairs in the 2015 samples were higher $(0.015-0.251)$ than those in the 1985 samples (0.003-0.101) (Fig. 5). Global $F_{\mathrm{ST}}$ was significantly lower among the 1985 samples $(0.048,95 \% \mathrm{CI}=$ $0.039-0.056)$ than among the 2015 samples $(0.125,95 \%$ CI $=0.109-0.146)$, indicating an increased genetic differentiation among the sites during the last 30 years.

BayesAss analysis showed that $95 \%$ of credible intervals of estimated recent migration overlapped with zero for almost all population pairs, indicating little or no recent gene flow among populations. There were significant migrations among six population pairs in the 1985 samples, but migrations decreased in three population pairs in the 2015 samples (Table 3).

\section{Discussion}

We found that the effective population size of M. ambigua continuously increased over the past 6000 years in concert with the expansion of semi-natural grassland habitat areas 


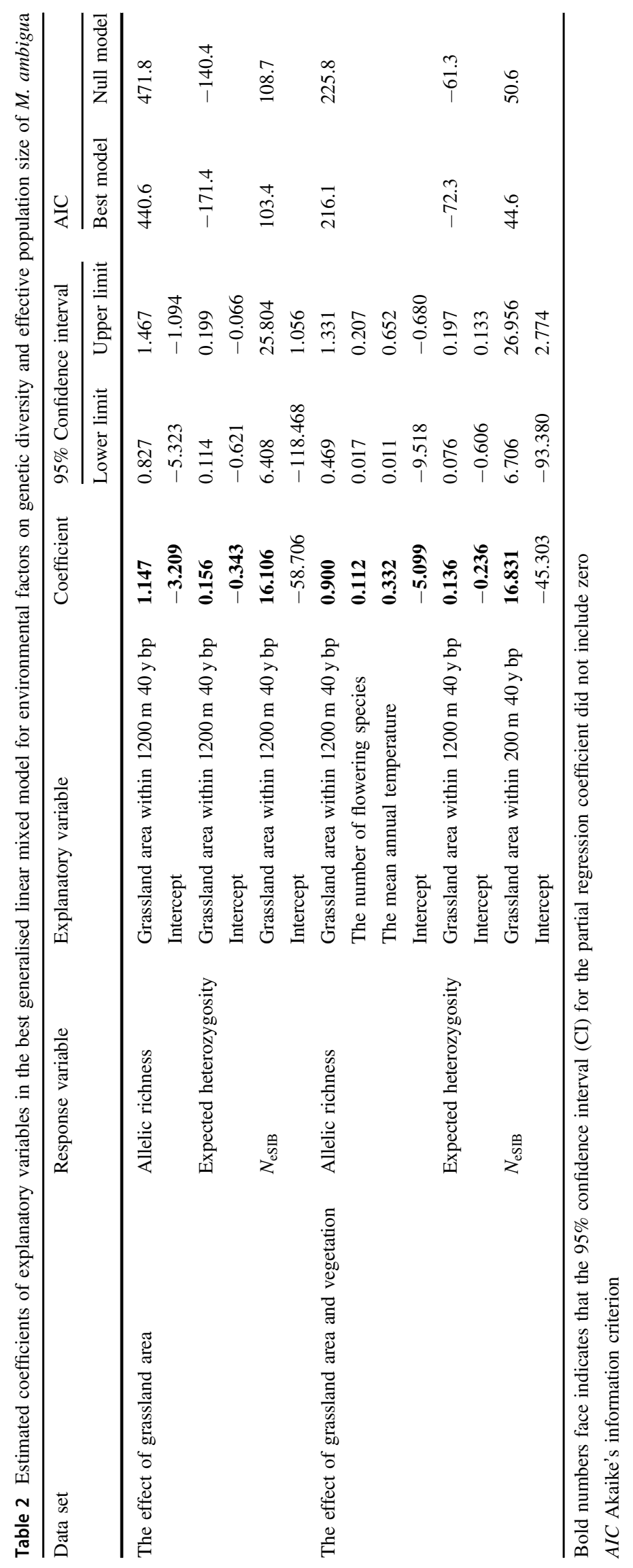



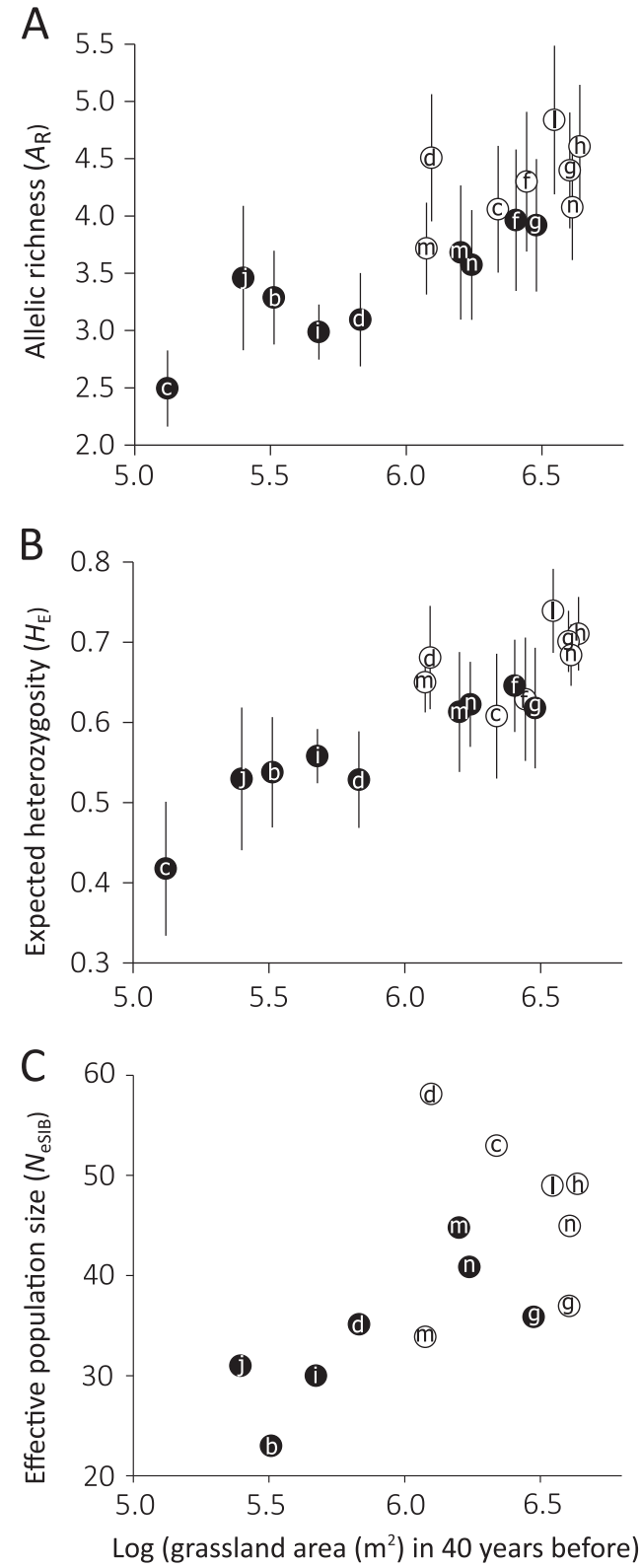

Fig. 3 Relationships between grassland area, and genetic diversity and effective population size in 1985 and 2015 samples. The horizontal axis shows the logarithmically transformed grassland area at $40 \mathrm{ybp}$ $\left(\mathrm{m}^{2}\right)$. The vertical axis shows allelic richness a, expected heterozygosity $\mathbf{b}$, and effective population size based on based on a sibship assignment analysis c. Open and black circles represent 1985 and 2015 samples, respectively. Bars indicate standard errors a, b

(Suka et al. 2011; Ushimaru et al. 2018). However, decreased genetic diversity and effective population sizes during recent decades in concert with rapid reductions in semi-natural grassland area might indicate the reduction in population sizes of $M$. ambigua. Our results further suggest that the demographic history of M. ambigua is consistent with the continuous loss, over time, of semi-natural grasslands in Japan. Furthermore, the recent reduction in grassland area has affected the genetic structure of $M$. ambigua in that the reduction and fragmentation of seminatural grasslands likely promoted higher genetic differentiation among remnant populations.

\section{Demographic history of $M$. ambigua during the Holocene}

Grassland butterfly populations in Japan separated from Russia populations approximately 72,000 y bp (95\% HPD $=21,000-148,000 \mathrm{ybp}$ ). In the last glacial period, the Tsushima Straits between the Japanese Archipelago and the Korean Peninsula narrowed due to sea level lowering (Oba and Irino 2012), during which time M. ambigua could have migrated to the Japan Archipelago. Thus, during this glacial period, there would be natural grasslands that supported $M$. ambigua populations because this species might have been distributed in Japan.

Our data indicate that $M$. ambigua expanded its population in Japan relatively recently (Fig. S3). Further, the population size of this species rapidly increased during $3000-6000 \mathrm{y} \mathrm{bp} \mathrm{(Fig.} \mathrm{2).} \mathrm{Before} \mathrm{the} \mathrm{last} \mathrm{glacial} \mathrm{period,}$ subalpine conifer forests and boreal grasslands dominated the highlands of the Chubu region, Japan (Yasuda and Narita 1981; Yoshida et al. 2016). The annual mean temperature was approximately $7^{\circ} \mathrm{C}$ lesser during this period than at present (Yasuda and Narita 1981), suggesting that cooler temperatures are unsuitable for M. ambigua and its larval host species, V. japonicum var. japonicum and $M$. laxum var. nikkoense. Phytolith and charcoal data (in Andosols) indicated that semi-natural grassland had begun to expand in the study area, spurred by anthropogenic activities about $3000-7000 \mathrm{ybp}$, which is consistent with the general trend of grassland expansion throughout Japan during the same period (Suka et al. 2011; Kawano et al. 2012; Miyabuchi et al. 2012; Yoshida et al. 2016; Ushimaru et al. 2018). Since 3000 y bp until relatively recently, widely occurring, semi-natural grasslands were maintained by humans to improve wildlife habitat, pasture domestic livestock, and maintain meadows (Suka et al. 2011; Ushimaru et al. 2018). Our results strongly suggest that the population expansion of $M$. ambigua coincides with the expansion of temperate semi-natural grasslands in Japan. The main larval host plants of M. ambigua still inhabit semi-natural grasslands in the study area. Furthermore, feeding opportunities (i.e., sources of nectar-providing plants) are prevalent and diverse in traditionally managed, semi-natural grasslands (Uchida and Ushimaru 2014; Uchida et al. 2016). Thus, an increase in larval and adult host plants due to semi-natural grassland expansion might have increased the population size of M. ambigua during the Holocene. 

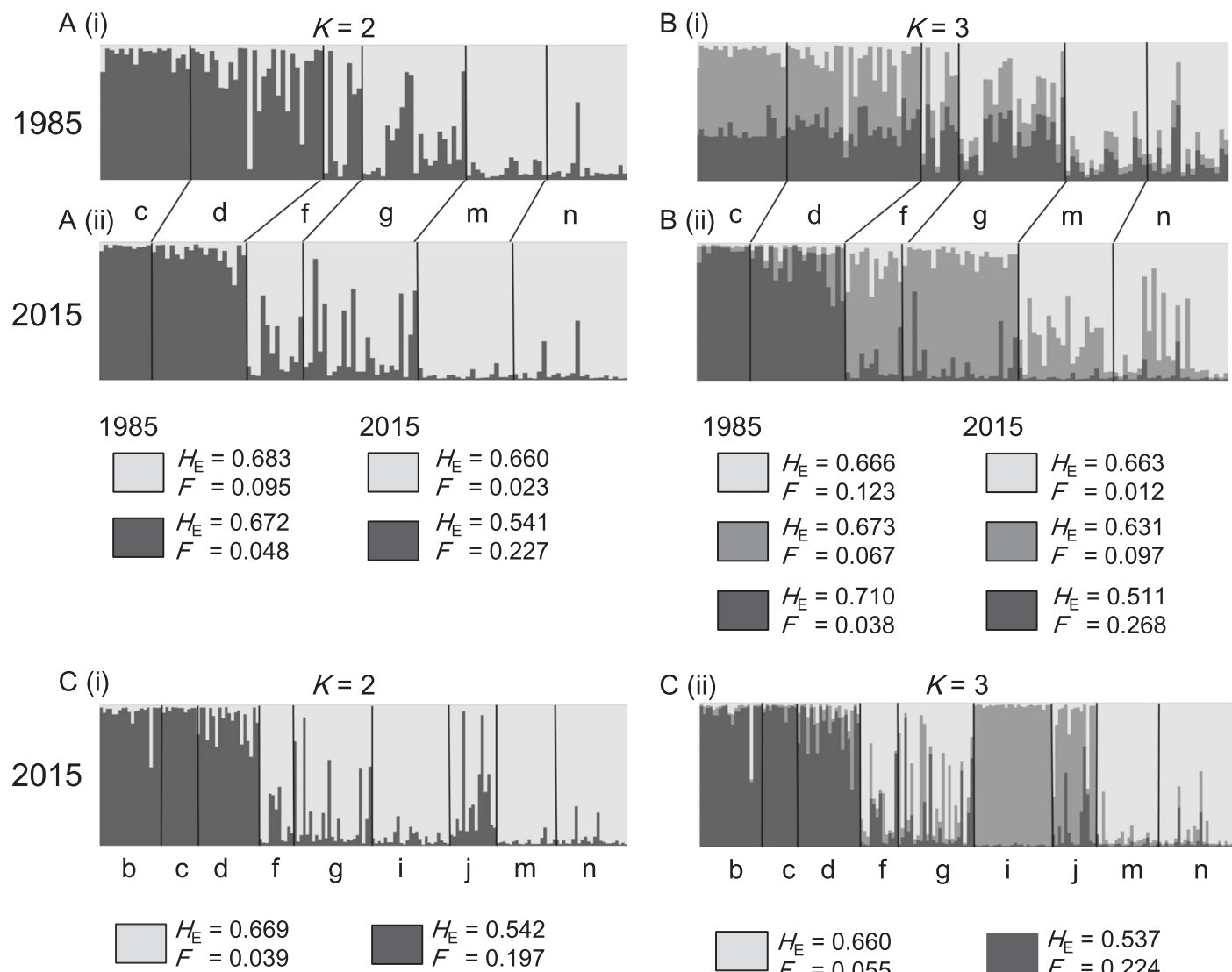

C (ii)

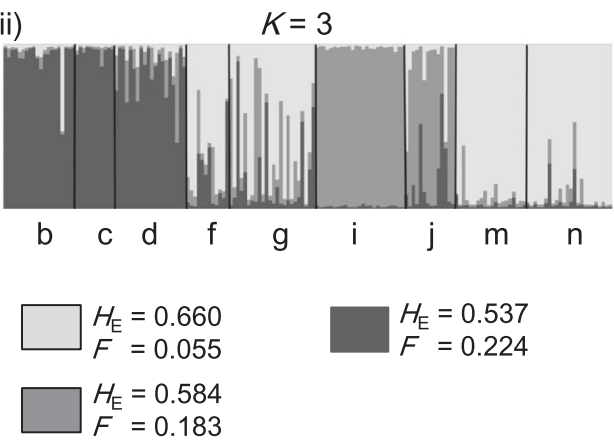

Fig. 4 a, b Genetic structure using STRUCTURE analysis of six populations in 1985 and 2015 (Pritchard et al. 2009). The proportion of the membership coefficient of 111individuals, six populations in 1985 (i) and 2015 (ii) for each of the inferred clusters for $K=2$ a and 3

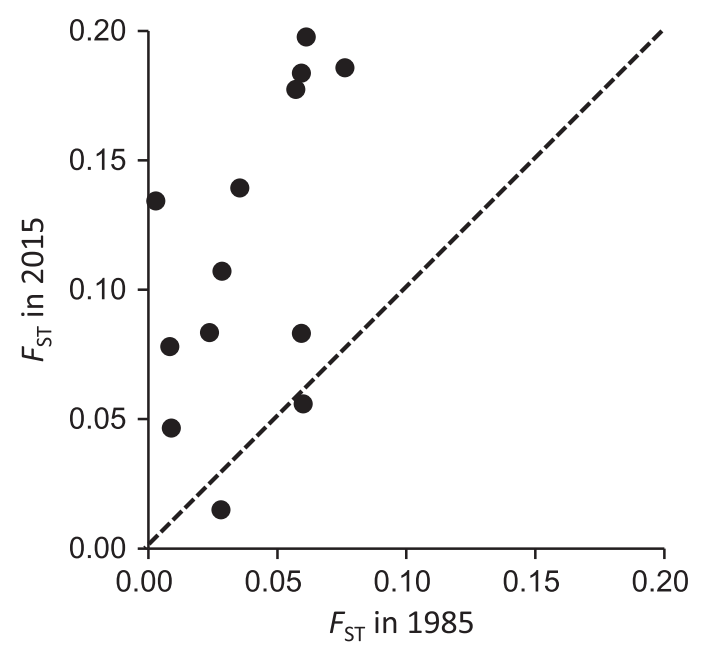

Fig. 5 Comparison of pairwise $F_{\mathrm{ST}}$ of six populations in 1985 and 2015 samples. The dotted line represents the case where the pairwise $F_{\text {ST }}$ would be equal in 1985 and 2015

b. c Genetic structure using STRUCTURE analysis of all populations in 2015. The proportion of the membership coefficient of 170 individuals, nine populations in 2015 for each of the inferred clusters for $K=2$ (i) and 3 (ii). Each column represents an individual

\section{Recent decline in genetic diversity}

There was a significant decrease in genetic diversity and effective population sizes over the last three decades in many M. ambigua populations (Fig. 3, S4), which is consistent with that population sizes recently declined. Genetic diversity is usually positively correlated with population size in organisms (Frankham 2009). The recorded number of M. ambigua populations has declined since the 1960s (Ministry of the Environment Government of Japan 2014). We identified five areas from which M. ambigua is now extinct. Our results suggest that the number of populations and the size of each population have rapidly declined in recent decades.

Our results showed the grassland area within 1200 (or 200) $\mathrm{m}$ radius in approximately $40 \mathrm{y}$ bp had a positive effect on the genetic diversity and effective population sizes of $M$. ambigua (Fig. 3). Although we used only grassland area but not the fragmentation index as the explanatory variable in LMM analyses due to strong correlation between the 
Table 3 (a) Estimates of migration rates (proportion of individuals) among six populations in ca. 1985, derived by BAYESASS

\begin{tabular}{|c|c|c|c|c|c|c|c|}
\hline & & \multicolumn{6}{|l|}{ Migration from } \\
\hline & & $\mathrm{c}$ & d & $\mathrm{f}$ & $\mathrm{g}$ & $\mathrm{m}$ & $\mathrm{n}$ \\
\hline \multirow[t]{12}{*}{ Migration into } & \multirow[t]{2}{*}{$\mathrm{c}$} & 0.680 & 0.265 & 0.013 & 0.014 & 0.014 & 0.014 \\
\hline & & $(0.655-0.705)$ & $(0.213-0.318)$ & $(0.000-0.038)$ & $(0.000-0.040)$ & $(0.000-0.040)$ & $(0.000-0.039)$ \\
\hline & \multirow[t]{2}{*}{$\mathrm{d}$} & 0.010 & 0.867 & 0.010 & 0.042 & 0.061 & 0.010 \\
\hline & & $(0.000-0.029)$ & $(0.797-0.938)$ & $(0.000-0.029)$ & $(0.000-0.104)$ & $(0.005-0.116)$ & $(0.000-0.029)$ \\
\hline & \multirow[t]{2}{*}{$\mathrm{f}$} & 0.024 & 0.051 & 0.690 & 0.092 & 0.119 & 0.024 \\
\hline & & $(0.000-0.067)$ & $(0.000-0.117)$ & $(0.648-0.733)$ & $(0.003-0.181)$ & $(0.027-0.211)$ & $(0.000-0.068)$ \\
\hline & \multirow[t]{2}{*}{$\mathrm{g}$} & 0.012 & 0.016 & 0.012 & 0.784 & 0.164 & 0.012 \\
\hline & & $(0.000-0.034)$ & $(0.000-0.046)$ & $(0.000-0.035)$ & $(0.715-0.852)$ & $(0.093-0.236)$ & $(0.000-034)$ \\
\hline & \multirow[t]{2}{*}{$\mathrm{m}$} & 0.015 & 0.016 & 0.014 & 0.043 & 0.897 & 0.015 \\
\hline & & $(0.000-0.042)$ & $(0.000-0.046)$ & $(0.000-0.041)$ & $(0.000-0.091)$ & $(0.832-0.962)$ & $(0.000-0.042)$ \\
\hline & \multirow[t]{2}{*}{$\mathrm{n}$} & 0.015 & 0.014 & 0.015 & 0.044 & 0.232 & 0.681 \\
\hline & & $(0.000-0.042)$ & $(0.000-0.041)$ & $(0.000-0.042)$ & $(0.000-0.089)$ & $(0.170-0.293)$ & $(0.654-0.708)$ \\
\hline
\end{tabular}

(b) Estimates of migration rates (proportion of individuals) among six populations in ca. 2015, derived by BAYESASS

\begin{tabular}{|c|c|c|c|c|c|c|c|}
\hline & & Migration from & & & & & \\
\hline & & $\mathrm{c}$ & d & $\mathrm{f}$ & $\mathrm{g}$ & $\mathrm{m}$ & $\mathrm{n}$ \\
\hline Migration into & $\mathrm{c}$ & 0.687 & 0.228 & 0.024 & 0.023 & 0.020 & 0.020 \\
\hline & & $(0.649-0.724)$ & $(0.152-0.303)$ & $(0.000-0.067)$ & $(0.000-0.066)$ & $(0.000-0.056)$ & $(0.000-0.055)$ \\
\hline & $\mathrm{d}$ & 0.014 & 0.888 & 0.019 & 0.045 & 0.017 & 0.017 \\
\hline & & $(0.000-0.039)$ & $(0.814-0.962)$ & $(0.000-0.055)$ & $(0.000-0.106)$ & $(0.000-0.048)$ & $(0.000-0.049)$ \\
\hline & $\mathrm{f}$ & 0.020 & 0.042 & 0.713 & 0.168 & 0.028 & 0.030 \\
\hline & & $(0.000-0.058)$ & $(0.000-0.109)$ & $(0.615-0.811)$ & $(0.032-0.304)$ & $(0.000-0.079)$ & $(0.000-0.084)$ \\
\hline & $\mathrm{g}$ & 0.013 & 0.019 & 0.066 & 0.852 & 0.031 & 0.019 \\
\hline & & $(0.000-0.039)$ & $(0.000-0.052)$ & $(0.000-0.205)$ & $(0.707-0.998)$ & $(0.000-0.086)$ & $(0.000-0.053)$ \\
\hline & $\mathrm{m}$ & 0.013 & 0.014 & 0.018 & 0.031 & 0.716 & 0.208 \\
\hline & & $(0.000-0.038)$ & $(0.000-0.041)$ & $(0.000-0.054)$ & $(0.000-0.093)$ & $(0.609-0.823)$ & $(0.085-0.330)$ \\
\hline & $\mathrm{n}$ & 0.012 & 0.015 & 0.025 & 0.026 & 0.018 & 0.905 \\
\hline & & $(0.000-0.034)$ & $(0.000-0.042)$ & $(0.000-0.069)$ & $(0.000-0.068)$ & $(0.000-0.055)$ & $(0.837-0.973)$ \\
\hline
\end{tabular}

Means of the posterior distributions of the migration rate into each population, are shown. The populations from which each individual was sampled are listed in the rows, whereas their populations from which they migrated are listed in the columns. Values along the diagonal are the proportions of individuals derived from the source populations each generation. Values in parentheses below migration rates are $95 \%$ CI. Bold numbers indicate that the $95 \%$ CI did not include zero

variables, habitat loss and fragmentation together might have negative effects on the genetic diversity and effective population sizes. It suggests that long-term maintenance of large grasslands is necessary for maintaining high genetic diversity and effective population sizes in M. ambigua. Other species of the same butterfly genus, (e.g., M. cinxia) have a maximum migration distance of about $1150 \mathrm{~m}$ (Kuussaari et al. 1996), consistent with our results concerning the size of grassland that most influences $M$. Ambigua genetic characteristics. The genetic diversity of grassland species is influenced by the size of its current grassland habitat and by its historical habitat area (Richmond et al. 2009; Kajtoch et al. 2014). We detected a strong effect of long-term (40 years) grassland maintenance on the genetic diversity of M. ambigua. Owing to limited aerial photograph records, we only compared changes in grassland area from recent records $(10 \mathrm{y} \mathrm{bp})$ and the recent past ( $40 \mathrm{ybp}$ ). Thus, we could not exactly determine the time required for maintaining a high genetic diversity in large grassland areas. Unfortunately, M. ambigua populations may experience a further decline in genetic diversity and effective population sizes in the future because we showed that grassland areas has been continuously declining in area since the 1970s in almost all study sites.

The number of flowering species and mean annual temperature also had positive effects on current $A_{\mathrm{R}}$ in 2015 . Because floral nectar is an important food resource for adult butterflies, the richness of flowering plants and butterfly species are known to be positively correlated (Uchida and Ushimaru 2014). Our study indicated that the richness of flowering plants also has a positive effect on genetic diversity of the endangered butterfly species. Conversely, 
we could not explain why annual temperature had a positive effect only on $A_{\mathrm{R}}$ (Table 2).

A decline in genetic diversity often increases the extinction probability by promoting inbreeding depression (Frankham 2009). M. cinxia (an isolated butterfly population with low genetic diversity) exhibits a high genetic load, which has caused declines in its development and reproductive performance (Mattila et al. 2012). In our study, the genetic diversity of $M$. ambigua rapidly declined recently, particularly in site c. Such a population may be vulnerable to extinction due to an expression of inbreeding depression and/or a high genetic load (Frankham 2009; Fountain et al. 2016)

\section{Increased genetic differentiation due to grassland loss and fragmentation}

Our results indicate that the loss and fragmentation of grasslands has led to an increase in genetic differentiation among M. ambigua populations since the 1980s (Figs. 4, 5), as it has in other wild species (Cousseau et al. 2016). Enhanced genetic differentiation in neutral loci among separated $M$. ambigua populations can be attributed to genetic drift and reduced migrations. Genetic drift due to declining population size might have caused random loss of rare alleles in populations, leading to enhanced genetic differentiation. In the Adonis blue butterfly, Harper et al. (2006) proposed that its allele frequency dramatically changed via genetic drift during the last 100 years. Furthermore, reduced migrations among populations may have also been responsible for this differentiation. Not only genetic drift but also reduced migrations caused decreased genetic diversity in fragmented black grouse populations of central Europe (Segelbacher et al. 2014). Inter-population migrations in $M$. ambigua may have become less frequent during the last 30 years (Table 3). Pronounced genetic differentiation is often delayed after habitat fragmentation reduces migration rates (Richmond et al. 2009). During the last three decades, gene flow among $M$. ambigua populations might be lower than rates before the 1980s because semi-natural grasslands in the study area have become smaller, more fragmented, and isolated.

\section{Conservation implications of $M$. ambigua}

The haplotype network of mitochondrial DNA showed no clear genetic structure among the sites in Japan, except for the Azumino populations (sites $\mathrm{i}$ and $\mathrm{j}$ ), although it also revealed the clear genetic differentiation between in Japanese and continental populations. Microsatellite marker data for the 2015 samples indicated that the Western Nagano (sites b, c, and d) and Azumino populations had unique clusters (Fig. 4c). Although the STRUCTURE analysis for six populations indicated that the clusters in the Chushin (sites $\mathrm{f}$ and $\mathrm{g}$ ) and Johshin (sites $\mathrm{m}$ and $\mathrm{n}$ ) regions were clearly separated in 2015, they had been similar in 1985 (Figs. 4a, b). Based on our results, each of these three populations (Western Nagano, Azumino and Chushin + Johshin) should be managed as three conservation units.

Grassland loss and fragmentation causes low genetic diversity and low population size in M. ambigua, which is also the case for most endangered species (Helm et al. 2009; Nakamura 2011); therefore, maintaining large and continuous, semi-natural grasslands is essential for conserving Japanese endemic $M$. ambigua populations (Nakamura 2011; Bubová et al. 2015). Uchida et al. (2016) reported that threatened butterflies and their host plants rapidly decreased due to the loss of traditional management practices in semi-natural grasslands in Japan. Furthermore, an increased population size of Japanese sika deer in the past two decades caused rapid declines in plant and herbivorous insect populations that rely on plants browsed on by the deer (Nakamura 2011). Overgrazing of herbaceous plants by sika deer has become obvious since 2009 in two of our sites (f and g) (Kishimoto et al. 2010), causing M. ambigua to become extinct at these sites, likely due to a large population decline in its larval host plant, $V$. japonicum. Therefore, resource managers should pay attention to sitespecific problems, in addition to addressing larger-scale problems such as loss of habitat and habitat fragmentation (Nakamura 2011; Uchida et al. 2016).

\section{Conclusion}

Our study demonstrated that the demography of an endangered grassland butterfly species can be traced to historical changes in its habitat. We also found that the genetic diversity, effective population sizes, and structure of $M$. ambigua were influenced by recent declines in grassland habitat. Loss of grassland habitat has occurred worldwide during the last several decades (Berg et al. 2011; Kleijn et al. 2011; Wright and Wimberly 2013 2013; Amici et al. 2015), resulting in a higher risk of extinction for many grassland butterfly species (Nakamura 2011; Bubová et al. 2015). Because land abandonment is the major cause for loss of grassland and its fragmentation (Ushimaru et al. 2018), it is necessary to continuously manage remaining areas and restore abandoned areas by reintroducing burning, grazing, and mowing.

\section{Data archiving}

Data available from the Dryad Digital Repository: https:// doi.org/10.5061/dryad.66471. 
Acknowledgements We are grateful to K Akita, T Dejima, S Dobata, T Inukai, Y Karouji, A Kato, H Kato, M Kobayashi, S Kondoh, H Kubo, K Maruyama, K Masui, H Matsumoto, I Matsumoto, S Minohara, T Mitani, S Miyake, S Mori, Y Nagahata, T Nakahashi, Y Namba, Y Nariyama, M Natsuaki, I Ohshima, K Ono, H Otobe, N Suzuki, H Takei, T Takeuchi, M Tanaka, M Tanikado, M Tashita, Y Tateiwa, K Toyoda and $\mathrm{H}$ Tuchida for donating specimen samples. We are also grateful to the Kanagawa Prefectural Museum of Natural History, Insect Museum of Shinshu, Itami City Museum of Insects, Lake Biwa Museum, Mie Prefectural Museum, Nagano Environmental Conservation Research Institute, Osaka Museum of Natural History, Toyohashi Museum of Natural History and Yokosuka City Museum for donating or loaning specimen samples. This work was supported by a Grant-in-Aid for Scientific Research (15J00908) from the Japan Society for the Promotion of Science.

\section{Compliance with ethical standards}

Conflict of interest The authors declare that they have no conflict of interest.

\section{References}

Amici V, Landi S, Frascaroli F, Rocchini D, Santi E, Chiarucci A (2015) Anthropogenic drivers of plant diversity: perspective on land use change in a dynamic cultural landscape. Biodivers Conserv 24:3185-3199

Bandelt HJ, Forster P, Röhl A (1999) Median-joining networks for inferring intraspecific phylogenies. Mol Biol Evol 16:37-48

Berg Å, Ahrné K, Öckinger E, Svensson R, Söderström B (2011) Butterfly distribution and abundance is affected by variation in the Swedish forest-farmland landscape. Biol Conserv 144:2819-2831

Bohn U, Neuhäusle R, Gollub G, Hettwer C, Neuhäuslová Z, Raus T, Schlüter H, Weber H (2003) Map of the natural vegetation of Europe. Explanatory text with CD-ROM. German Federal Agency for Nature Conservation, Bonn

Bubová T, Vrabec V, Kulma M, Nowicki P (2015) Land management impacts on European butterflies of conservation concern: a review. J Insect Conserv 19:805-821

Cousseau L, Husemann M, Foppen R, Vangestel C, Lens L (2016) A longitudinal genetic survey identifies temporal shifts in the population structure of Dutch house sparrows. Heredity 117:259-267

Darriba D, Taboada GL, Doallo R, Posada D (2012) jModelTest 2: more models, new heuristics and parallel computing. Nat Methods 9:772

Do C, Waples RS, Peel D, Macbeth GM, Tillett BJ, Ovenden JR (2014) NeEstimatorv2: reimplementation of software for the estimation of contemporary effective population size $(\mathrm{N} e)$ from genetic data. Mol Ecol Resour 14:209-214

Drummond AJ, Rambaut A (2007) BEAST: Bayesian evolutionary analysis by sampling trees. BMC Evol Biol 7:214

Excoffier L, Laval G, Schneider S (2005) ARLEQUIN (version 3.0): an integrated software package for population genetics data analysis. Evol Bioinform 1:47-50

Fountain T, Nieminen M, Sirén J, Wong SC, Hanski I (2016) Predictable allele frequency changes due to habitat fragmentation in the Glanville fritillary butterfly. Proc Natl Acad Sci USA 113:2678-2683

Frankham R (2009) Introduction to conservation genetics, Second Edition. Cambridge University Press, Cambridge, Google Earth (c) 2016 ZENRIN (2016). Google Earth. Available at https://earth. google.com/web/. Accessed 1 Jul 2016
Goudet J (2001) FSTAT; A program to estimate and test gene diversities and fixation indices version 2.9.3. Available at Available at http://www2.unil.ch/popgen/softwares/fstat.html. Accessed 1 Oct 2015

Hamm CA, Aggarwal D, Landis DA (2010) Evaluating the impact of non-lethal DNA sampling on two butterflies, Vanessa cardui and Satyrodes eurydice. J Insect Conserv 14:11-18

Harper GL, Maclean N, Goulson D (2006) Analysis of museum specimens suggests extreme genetic drift in the adonis blue butterfly (Polyommatus bellargus). Biol J Linn Soc 88:447-452

Hejcman M, Hejcmanová P, Pavlu V, Beneš J (2013) Origin and history of grasslands in Central Europe-a review. Grass Forage Sci 68:345-363

Helm A, Oja T, Saar L, Takkis K, Talve T, Pärtel M (2009) Human influence lowers plant genetic diversity in communities with extinction debt. J Ecol 97:1329-1336

Higgins D, Thompson J, Gibson T, Thompson JD, Higgins DG, Gibson TJ (1994) CLUSTAL W: improving the sensitivity of progressive multiple sequence alignment through sequence weighting, position-specific gap penalties and weight matrix choice. Nucleic Acids Res 22:4673-4680

Isselstein J, Jeangros B, Pavlu V (2005) Agronomic aspects of biodiversity targeted management of temperate grasslands in Europe-a review. Agron Res 3:139-151

Kajtoch Ł, Mazur M, Kubisz D, Mazur MA, Babik W (2014) Low effective population sizes and limited connectivity in xerothermic beetles: implications for the conservation of an endangered habitat. Anim Conserv 17:454-466

Kawano T, Sasaki N, Hayashi T, Takahara H (2012) Grassland and fire history since the late-glacial in northern part of Aso Caldera, central Kyusyu, Japan, inferred from phytolith and charcoal records. Quatern Int 254:18-27

Kishimoto R, Aizawa H, Yoshioka M, Ishida Y, Mitsui K, Suga S (2010) Population dynamics of sika deer Cervus nippon monitored by spotlight-census in Kirigamine, central Japan. Bull Nagano Environ Conserv Res Inst 6:13-16 (in Japanese)

Kleijn D, Rundlöf M, Scheper J, Smith HG, Tscharntke T (2011) Does conservation on farmland contribute to halting the biodiversity decline? Trends Ecol Evol 26:474-481

Koyanagi TF, Furukawa T (2013) Nation-wide agrarian depopulation threatens semi-natural grassland species in Japan: sub-national application of the Red List Index. Biol Conserv 167:1-8

Kuneš P, Svobodová-Svitavská H, Kolář J, Hajnalová M, Abraham V, Macek M, Tkáč P, Szabó P (2015) The origin of grasslands in the temperate forest zone of east-central Europe: long-term legacy of climate and human impact. Quat Sci Rev 116:15-27

Kuussaari M, Nieminen M, Hanski I (1996) An experimental study of migration in the Glanville fritillary butterfly Melitaea cinxia. J Anim Ecol 65:791-801

Mattila AL, Duplouy A, Kirjokangas M, Lehtonen R, Rastas P, Hanski I (2012) High genetic load in an old isolated butterfly population. Proc Natl Acad Sci USA 109:2496-2505

Ministry of the Environment Government of Japan (2014) Threatened wildlife of japan —red data book, Insects. Japan Wildlife Research Center, Tokyo (in Japanese)

Miyabuchi Y, Sugiyama S, Nagaoka Y (2012) Vegetation and fire history during the last 30000 years based on phytolith and macroscopic charcoal records in the eastern and western areas of Aso Volcano, Japan. Quatern Int 254:28-35

Miyawaki A, Okuda S, Suzuki K (1975) Potential natural vegetation map of Japan. In: Numata M, Yoshioka K, Kato M (eds) Studies in conservation of natural terrestrial ecosystems in Japan, JIBP Synthesis. University of Tokyo Press, Tokyo, p. 22-23

Nakahama N, Isagi Y (2017) Availability of short microsatellite markers from butterfly museums and private specimens. Entomol Sci 20:3-6 
Nakahama N, Izuno A, Arima K, Isagi Y (2015) Development of microsatellite markers for two endangered grassland butterflies, Melitaea ambigua and M. protomedia (Nymphalidae), using Ion Torrent next-generation sequencing. Conserv Genet Resour 7:525-527

Nakamura Y (2011) Conservation of butterflies in Japan: status, actions and strategy. J Insect Conserv 15:5-22

Oba T, Irino T (2012) Sea level at the last glacial maximum, constrained by oxygen isotopic curves of planktonic foraminifera in the Japan Sea. J Quat Sci 27:941-947

Ogura J (2006) The transition of grassland area in Japan. J Kyoto Seika Univ 30:160-172 (in Japanese)

Papadopoulou A, Anastasiou I, Vogler AP (2010) Revisiting the insect mitochondrial molecular clock: the mid-Aegean trench calibration. Mol Biol Evol 27:1659-1672

Pritchard JK, Wen X, Falshu D (2009) Documentation for STRUCTURE ver. 2.3. University of Chicago, Chicago

Rambaut A, Suchard M, Xie W, Drummond A (2014). Tracer v. 1.6. University of Edinburgh. Institute of Evolutionary Biology, Edinburgh.

R Development Core Team (2015) R: a language and environment for statistical computing. R Foundation for Statistical Computing, Vienna

Richmond JQ, Reid DT, Ashton KG, Zamudio KR (2009) Delayed genetic effects of habitat fragmentation on the ecologically specialized Florida sand skink (Plestiodon reynoldsi). Conserv Genet 10:1281-1297

Segelbacher G, Strand TM, Quintela M, Axelsson T, Jansman HA, Koelewijn HP, Höglund J (2014) Analyses of historical and current populations of black grouse in Central Europe reveal strong effects of genetic drift and loss of genetic diversity. Conserv Genet 15:1183-1195

Shirouzu T (2006) The butterflies of Japan in color. Gakken, Tokyo (in Japanese)

Stojak J, McDevitt AD, Herman JS, Searle JB, Wójcik JM (2015) Post-glacial colonization of eastern Europe from the Carpathian refugium: evidence from mitochondrial DNA of the common vole Microtus arvalis. Biol J Linn Soc 115:927-939

Suka T, Ushimaru A, Tanaka H (2011) Grassland history and grassland fauna and flora in the Japanese Archipelago. In: Yumoto T (ed.) Environmental history of grassfields in Japan. Bun-ichi, Tokyo, pp 101-122.

Tamura K, Stecher G, Peterson D, Filipski A, Kumar S (2013) MEGA6: molecular evolutionary genetics analysis version 6.0. Mol Biol Evol 30:2725-2729

Török P, Dengler J (2018). Palaearctic grasslands in transition: overarching patterns and future prospects. In: Squires VR, Dengler J,
Feng H, Hua, L (eds) Grassland management: problems and prospects. CRC Press, Boca Raton, US (in press)

Török P, Janišová M, Kuzemko A, Rusina S, Dajić Stevanovic Z (2018). Grasslands, their threats and management in Eastern Europe. In: Squires VR, Dengler J, Feng H, Hua L (eds) Grassland management: problems and prospects. CRC Press, Boca Raton, US (in press)

Turner MG, Gardner RH, O'Neill RV (2001) Landscape ecology in theory and practice pattern and process. Springer, New York

Uchida K, Takahashi S, Shinohara T, Ushimaru A (2016) Threatened herbivorous insects maintained by long-term traditional management practices in semi-natural grasslands. Agric Ecosyst Environ 221:156-162

Uchida K, Ushimaru A (2014) Biodiversity declines due to abandonment and intensification of agricultural lands: patterns and mechanisms. Ecol Monogr 84:637-658

Ushimaru A, Uchida K, Suka T (2018) Grassland biodiversity in Japan: threats, management and conservation. In: Squires VR, Dengler J, Feng H, Hua L (eds) Grassland management: problems and prospects. CRC Press, Boca Raton, US, (in press)

Van Oosterhout C, Hutchinson WF, Wills DP, Shipley P (2004) MICRO-CHECKER: software for identifying and correcting genotyping errors in microsatellite data. Mol Ecol Notes 4:535-538

Wandeler P, Hoeck PE, Keller LF (2007) Back to the future: museum specimens in population genetics. Trends Ecol Evol 22:634-642

Wang J (2009) A new method for estimating effective population sizes from a single sample of multilocus genotypes. Mol Ecol 18:2148-2164

Wilson GA, Rannala B (2003) Bayesian inference of recent migration rates using multilocus genotypes. Genetics 163:1177-1191

Wright CK, Wimberly MC (2013) Recent land use change in the Western Corn Belt threatens grasslands and wetlands. Proc Natl Acad Sci USA 110:4134-4139

Yasuda Y, Narita K (1981) Calculated thermal index maps for the reconstruction of past vegetation since the last glacial age in Japan. Geogr Rev Jpn 54:369-381 (in Japanese with English summary)

Yoshida A, Kudo Y, Shimada K, Hashizume J, Ono A (2016) Impact of landscape changes on obsidian exploitation since the Palaeolithic in the central highland of Japan. Veg Hist Archaeobot 25:45-55

Yuan QZ, Zhao DS, Wu SH, Dai EF (2011) Validation of the integrated biosphere simulator in simulating the potential natural vegetation map of China. Ecol Res 26:917-929 